\title{
Emergency medicine as a career choice: a descriptive study of Canadian medical students
}

\author{
Ian M. Scott, MD, MSc; ${ }^{*}$ Riyad B. Abu-Laban, MD, MHSc; ${ }^{\dagger}$ Margot C. Gowans, BSc, Grad, Dip Clin Epi; ${ }^{*}$ \\ Bruce J. Wright, MD; ${ }^{\ddagger}$ Fraser R. Brenneis, MD ${ }^{\S}$
}

\section{See related article on page 240}

\section{ABSTRACT}

Background: Studies indicate that a student's career interest at medical school entry is related to his or her ultimate career. We sought to determine the level of interest in emergency medicine among students at the time of medical school entry, and to describe characteristics associated with students primarily interested in emergency medicine.

Methods: We surveyed students in 18 medical school classes from 8 Canadian universities between 2001 and 2004 at the commencement of their studies. Participants listed their top career choice and the degree to which a series of variables influenced their choices. We also collected demographic data.

Results: Of 2420 surveys distributed, 2168 (89.6\%) were completed. A total of $6.1 \%$ (95\% confidence interval $5.1 \%-7.1 \%$ ) of respondents cited emergency medicine as their first career choice. When compared with students primarily interested in family medicine, those primarily interested in emergency medicine reported a greater influence of hospital orientation and a lesser influence of social orientation on their career choice. When compared with students primarily interested in the surgical specialties, those primarily interested in emergency medicine were more likely to report medical lifestyle and varied scope of practice as important influences. When compared with students primarily interested in the medical specialties, those who reported interest in emergency medicine were more likely to report that a hospital orientation and varied scope of practice were important influences, and less likely to report that social orientation was important.

Conclusion: Students primarily interested in emergency medicine at medical school entry have attributes that differentiate them from students primarily interested in family medicine, the surgical specialties or the medical specialties. These findings may help guide future initiatives regarding emergency medicine education.
Keywords: education, medical, undergraduate, career choice, specialties, emergency medicine, medical student, medical school

\section{RÉSUMÉ}

Contexte : Des études révèlent l'existence d'un lien entre le domaine professionnel qui intéresse l'étudiant au moment de son entrée à la faculté de médecine et la carrière qu'il choisit au final. Nous avons voulu déterminer le degré d'intérêt à l'endroit de la médecine d'urgence chez les étudiants au moment de leur entrée à la faculté de médecine et décrire les caractéristiques de ceux qui manifestaient un intérêt particulier pour ce domaine.

Méthodes : Nous avons réalisé un sondage auprès d'étudiants inscrits à 18 cours de médecine de 8 universités canadiennes entre 2001 et 2004, au début de leurs études. Les participants ont dressé la liste de leurs préférences en matière de choix de carrière et indiqué à quel degré une série de variables influait sur leurs choix. Nous avons aussi recueilli des données démographiques.

Résultats : Sur les 2420 questionnaires distribués, 2168 $(89,6 \%)$ ont été remplis. En tout, $6,1 \%$ (intervalle de confiance à $95 \%$ de 5,1 à 7,1\%) des répondants ont classé la médecine d'urgence au premier rang parmi leurs choix de carrière. Comparativement aux étudiants qui s'intéressaient principalement à la médecine familiale, les répondants attirés surtout par la médecine d'urgence ont mentionné que I'orientation hospitalière avait eu plus d'influence que l'orientation sociale sur leur choix de carrière. Comparativement aux étudiants qui s'intéressaient principalement à la chirurgie, les répondants attirés surtout par la médecine $\mathrm{d}^{\prime}$ urgence étaient plus susceptibles de mentionner le mode de vie et la diversité associés à cette pratique comme facteurs ayant influé sur leur choix. Comparativement aux étudiants qui s'intéressaient principalement aux spécialités médicales, les répondants attirés surtout par la médecine d'urgence étaient plus susceptibles d'affirmer avoir été influ-

From the Departments of *Family Practice and †Emergency Medicine, University of British Columbia, Vancouver, BC, the $¥ D$ Department of Family Medicine, University of Calgary, Calgary, Alta., and the §Department of Family Medicine, University of Alberta, Edmonton, Alta.

Submitted May 27, 2008; Revised Oct. 28, 2008; Accepted Nov. 25, 2008

This article has been peer reviewed.

CJEM 2009;11(3):196-206

$1962009 ; 11(3)$

$C J E M \bullet J C M U$ 
encés par l'orientation hospitalière et la diversité de la pratique et moins susceptibles d'accorder de l'importance à I'influence de l'orientation sociale.

Conclusion : Les étudiants qui s'intéressent principalement à la médecine d'urgence lorsqu'ils entrent à la faculté de médecine présentent des caractéristiques qui les distinguent des étudiants attirés davantage par la médecine familiale et les spécialités chirurgicales ou médicales. Ces observations pourraient servir à guider d'éventuelles initiatives touchant la formation en médecine d'urgence.

\section{INTRODUCTION}

Emergency medicine is a relatively new specialty in Canada with 2 routes of certification. The first Canadian emergency medicine certification exams were held by the College of Family Physicians of Canada (CFPC) in 1982 and by the Royal College of Physicians and Surgeons of Canada (RCPSC) in $1983 .{ }^{1}$

Emergency medicine is a unique specialty, which involves rapidly diagnosing, treating and arranging disposition for patients with acute conditions. Emergency physicians must possess a broad knowledge base that encompasses all areas of medicine; they are often forced to make rapid decisions based on limited or incomplete information. The ability to multitask, deal with interruptions and manage numerous patients simultaneously are key characteristics of seasoned emergency physicians. ${ }^{2}$ Although primers have been written that offer guidance on working efficiently in the emergency department setting, ${ }^{3}$ little research has been performed on the personality characteristics or traits that emergency physicians possess. In 1993, a study was published describing the heterogeneous Canadian emergency medicine workforce. ${ }^{4}$ The characteristics of full-time emergency physicians in Canada are likely to have changed in the 15 years since the publication of this study, in part because of the increasing number of residencytrained emergency physicians.

Between 2000 and 2007, the number of available RCPSC residency positions increased from 19 to 44 positions. ${ }^{5}$ During that same period, the number of medical students vying for these positions as their first choice of residency rose from 28 to $60(2.8 \%-4.2 \%)$ of all Canadian graduates. ${ }^{5}$ The number of CCFP-EM training positions has also increased from 85 residents in 2000 to 110 residents in 2007 (Les Forward, Database Manager, Canadian Post-MD, Education Registry (CAPER), Ottawa, Ont.: personal communication, 2008). These statistics indicate that the degree of interest in emergency medicine in Canada exceeds the available training opportunities. This situation is not found in the United States where there are more emergency medicine positions than American senior medical students applying for them. ${ }^{6}$
Several studies have compared the factors associated with a primary care career choice with a nonprimary care career choice. Few studies, however, have focused on what motivates students to choose a career in emergency medicine, which is frequently described as a career option in which lifestyle is controllable. Some feel that this perception is responsible for students' choice..$^{7-9}$ Final-year medical students interviewing for emergency medicine residencies report that diversity in clinical pathology, emphasis on acute care, previous work in an emergency setting and flexibility of both practice location and work schedule are important factors in their career choice. ${ }^{10}$ The mere presence of an emergency medicine clerkship does not appear to be associated with a greater interest in a career in emergency medicine. ${ }^{11}$

Our purpose was to describe the level of interest in emergency medicine as a career among students at the time of medical school entry, and to report comparative characteristics associated with students interested in emergency medicine. This analysis is a substudy of previously published investigations on medical student career choices. ${ }^{12-16}$

\section{METHODS}

Between 2001 and 2004, we distributed a 41-item survey (Appendix 1) to all students in 18 Canadian medical school classes from 8 universities within 2 weeks of the commencement of their medical studies. Not all schools were surveyed every year, and international students were excluded. We selected the survey items based on a literature review and consultations with medical students, residents, physicians and educational leaders. Before beginning the study, we distributed the survey to medical students, residents, physicians and content experts to verify item comprehensiveness and appropriateness. We piloted a draft survey with 1 class, and then modified the survey instrument following this validation process. ${ }^{15}$ We studied 4 classes from both the University of British Columbia (2001-2004) and the University of Calgary (2001-2004); 2 classes each from the University of Toronto (2003/04), McMaster University 
(2003/04), Queen's University (2003/04) and the University of Western Ontario (2003/04); and 1 class each from the University of Alberta (2002) and the University of Ottawa (2003).

The survey asked students to consider 8 career options: emergency medicine, family medicine, internal medicine, obstetrics and gynecology, pediatrics, psychiatry, surgery and "other" (a write-in choice). They were then asked to indicate with a "yes" or "no" what they would consider a possible career and to rank their top 3 career choices. Students were not asked their choice of the 2 Canadian emergency medicine certification streams; only the more general option of emergency medicine was provided. As subjects were very early in their medical training, we felt it would not be helpful to seek information categorized by the emergency medicine certification stream. Students then evaluated the extent to which 27 variables (Table 1) influenced their first choice, using a 5 -point Likert scale ranging from 1 (no influence) to 5 (major influence). Demographic data were also collected.

In order to limit the number of statistical tests and reduce the possibility of spuriously significant results, we collapsed student career choices into 3 groups according to the classification used by the Canadian Institute for Health Information. ${ }^{17}$ These groups included family medicine, medical specialties and surgical specialties. Where applicable, we recoded responses listed as "other" using explicit criteria into 1 of these 3 broad career categories. We excluded emergency medicine from the medical specialties category where it is classified by the Canadian Institute for

Table 1. Variables that influence students' career interests at medical school entry

\begin{tabular}{|c|c|c|c|c|c|c|}
\hline \multirow[b]{2}{*}{ Variable } & \multicolumn{4}{|c|}{$\%$ of students } & \multicolumn{2}{|c|}{ Results of ANOVA } \\
\hline & $\begin{array}{c}a \\
\text { Emergency } \\
\text { medicine, } \\
n=128\end{array}$ & $\begin{array}{c}b \\
\text { Family } \\
\text { medicine, } \\
n=545\end{array}$ & $\begin{array}{c}\text { c } \\
\text { Surgical } \\
\text { specialty, } \\
n=441\end{array}$ & $\begin{array}{c}d \\
\text { Medical } \\
\text { speciality, } \\
n=982\end{array}$ & $\mathrm{~F}$ & $p$ value \\
\hline A. Wide variety of patient problems & $4.45^{c, d}$ & $4.33^{c, d}$ & $3.11^{a, b}$ & $3.26^{\mathrm{a}, \mathrm{b}}$ & 173.89 & $<0.001$ \\
\hline B. Narrower variety of patient problems & $1.96^{\mathrm{c}, \mathrm{d}}$ & $2.01^{\mathrm{c}, \mathrm{d}}$ & $3.25^{\mathrm{a}, \mathrm{b}}$ & $3.15^{a, b}$ & 163.24 & $<0.001$ \\
\hline C. Good match to career & 2.21 & $2.04^{\mathrm{c}, \mathrm{d}}$ & $2.28^{b}$ & $2.35^{\mathrm{b}}$ & 6.43 & $<0.001$ \\
\hline D. Patient population is interesting & $4.48^{\circ}$ & $4.39^{\circ}$ & $3.98^{a, b, d}$ & $4.30^{\circ}$ & 22.71 & $<0.001$ \\
\hline E. Focus on in-hospital care & $3.48^{\mathrm{b}, \mathrm{d}}$ & $2.14^{\mathrm{a}, \mathrm{c}, \mathrm{d}}$ & $3.35^{b, d}$ & $3.10^{a, b, c}$ & 116.85 & $<0.001$ \\
\hline F. Focus on patients in community & $2.91^{\mathrm{b}}$ & $4.26^{a, c, d}$ & $2.70^{\mathrm{b}, \mathrm{d}}$ & $3.11^{\mathrm{b}, \mathrm{c}}$ & 196.93 & $<0.001$ \\
\hline G. Focus on urgent care & $4.39^{b, c, d}$ & $2.50^{a, o, d}$ & $3.36^{a, b, d}$ & $2.84^{\mathrm{a}, \mathrm{b}, \mathrm{c}}$ & 113.48 & $<0.001$ \\
\hline H. Focus on nonurgent care & $1.89^{b, c, d}$ & $3.05^{a, o, d}$ & $2.41^{a, b, d}$ & $2.69^{a, b, c}$ & 50.57 & $<0.001$ \\
\hline I. Intervention results immediate & $3.85^{b, d}$ & $2.60^{a, c, d}$ & $3.79^{b, d}$ & $2.95^{\mathrm{a}, \mathrm{b}, \mathrm{c}}$ & 114.95 & $<0.001$ \\
\hline J. Adequate income to eliminate debt & 2.22 & $1.95^{\circ}$ & $2.24^{\mathrm{b}}$ & 2.12 & 4.37 & 0.005 \\
\hline K. High income potential & $2.19^{\mathrm{b}}$ & $1.83^{\mathrm{a}, \mathrm{cod}}$ & $2.44^{\mathrm{b}, \mathrm{d}}$ & $2.19^{b, c}$ & 24.74 & $<0.001$ \\
\hline L. Long-term patient relationship & $2.39^{b, d}$ & $4.11^{\mathrm{a}, \mathrm{c}, \mathrm{d}}$ & $2.61^{\mathrm{b}, \mathrm{d}}$ & $3.28^{\mathrm{a}, \mathrm{b}, \mathrm{c}}$ & 191.21 & $<0.001$ \\
\hline M. Status among colleagues & 1.93 & $1.66^{\mathrm{cdd}}$ & $2.12^{b}$ & $2.02^{b}$ & 18.82 & $<0.001$ \\
\hline N. Acceptable on-call schedule & $3.39^{c}$ & $3.57^{c}$ & $2.84^{a, b, d}$ & $3.41^{\circ}$ & 34.82 & $<0.001$ \\
\hline O. Don't like uncertainty & $1.92^{c}$ & $2.04^{\circ}$ & $2.31^{\mathrm{a}, \mathrm{b}}$ & 2.16 & 7.21 & $<0.001$ \\
\hline P. Prefer medical to social problems & $2.84^{\mathrm{b}}$ & $1.96^{a, c, d}$ & $3.19^{b, d}$ & $2.59^{\mathrm{b}, \mathrm{c}}$ & 77.46 & $<0.001$ \\
\hline Q. Emulate physician & 2.47 & 2.62 & 2.44 & 2.54 & 1.29 & 0.28 \\
\hline R. Research interest & $2.15^{c, d}$ & $1.80^{\mathrm{c}, \mathrm{d}}$ & $2.68^{\mathrm{a}, \mathrm{b}}$ & $2.79^{\mathrm{a}, \mathrm{b}}$ & 69.10 & $<0.001$ \\
\hline S. Social commitment & $3.06^{\mathrm{b}}$ & $3.71^{a, c, d}$ & $2.98^{\mathrm{b}, \mathrm{d}}$ & $3.26^{\mathrm{b}, \mathrm{c}}$ & 32.00 & $<0.001$ \\
\hline T. Stable/secure future & 1.73 & 1.74 & 1.81 & 1.87 & 1.74 & 0.16 \\
\hline U. Health promotion is important & $3.38^{\mathrm{b}}$ & $4.24^{a, c, d}$ & $3.20^{\mathrm{b}, \mathrm{d}}$ & $3.54^{b, c}$ & 81.69 & $<0.001$ \\
\hline V. Acceptable hours of practice & $3.31^{\mathrm{b}, \mathrm{c}}$ & $3.82^{a, c, d}$ & $2.83^{a, b, d}$ & $3.43^{\mathrm{b}, \mathrm{c}}$ & 55.33 & $<0.001$ \\
\hline W. Flexibility inside of medicine & $3.97^{\circ}$ & $4.13^{\mathrm{c}, \mathrm{d}}$ & $3.51^{a, b, d}$ & $3.83^{\mathrm{b}, \mathrm{c}}$ & 30.98 & $<0.001$ \\
\hline X. Flexibility outside of medicine & $3.77^{\circ}$ & $4.00^{c, d}$ & $3.19^{a, b, d}$ & $3.65^{\mathrm{b}, \mathrm{c}}$ & 47.74 & $<0.001$ \\
\hline Y. $\quad$ Keep options open & $3.74^{c}$ & $3.80^{c, d}$ & $3.29^{a, b, d}$ & $3.58^{\mathrm{b}, \mathrm{c}}$ & 18.85 & $<0.001$ \\
\hline Z. Meaningful past experience & 3.00 & 3.04 & 2.87 & 3.00 & 1.47 & 0.22 \\
\hline AA. Short postgraduate training & $1.85^{\mathrm{b}, \mathrm{c}}$ & $2.50^{a, c, d}$ & $1.49^{a, b, d}$ & $1.71^{\mathrm{b}, \mathrm{c}}$ & 104.81 & $<0.001$ \\
\hline
\end{tabular}


Health Information, thus allowing students who indicated an interest in emergency medicine to be compared with other students who were interested in each of the other 3 broad career options.

We performed data analysis using SPSS version 14.0 (SPSS Inc.). We used descriptive statistics to profile the students who were interested in emergency medicine and unpaired $t$ tests to identify differences in the career influences according to career interest. We performed factor analysis to reduce the 27 career influences into a smaller number of overarching factors. Factors were included if they had an eigenvalue greater than 1 and variables were included if they had factor loadings greater then 0.5. We derived descriptive names for the resulting factors, such as the term "social orientation," according to the items that loaded into each factor (Box 1). Unpaired $t$ tests were then used to identify differences in the resulting factors according to career. $P$ values less

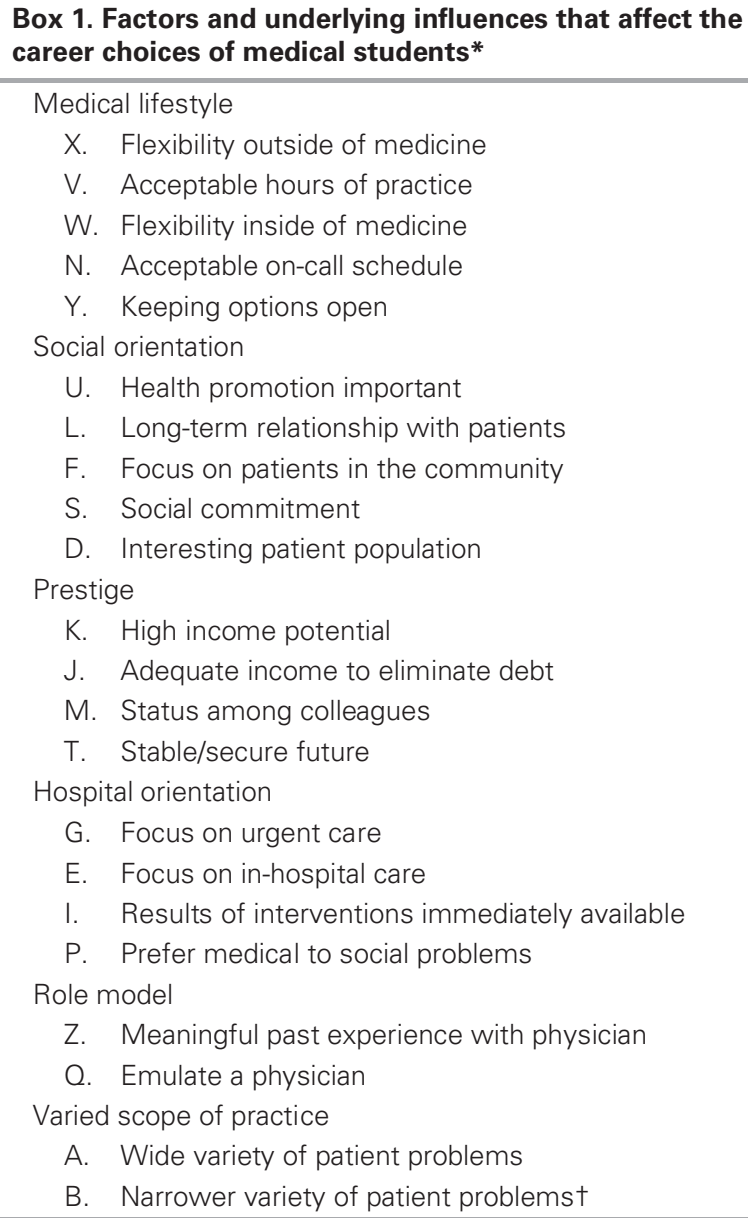

* For each factor, the average of the Likert scores for items in that factor was computed. Analysis of variance was then used to compare factor scores according to career choice.

tRecoded in reverse order as going in opposite direction to other influence in factor. than or equal to 0.05 were deemed to be statistically significant.

\section{RESULTS}

Of the 2420 surveys distributed, 2168 (89.6\%) students responded. Seventy-two surveys were excluded because the student failed to indicate a specific career preference. Of the remaining 2096 surveys, 128 (6.1\%, 95\% confidence interval [CI] 5.1\%-7.1\%) cited emergency medicine as their top career choice. An additional 1106 students $(52.8 \%, 95 \%$ CI $50.7 \%-54.9 \%)$ indicated that they would consider a career in emergency medicine, though not as their top career choice. When combined, these results indicated that $58.9 \%$ of students $(95 \% \mathrm{CI}$

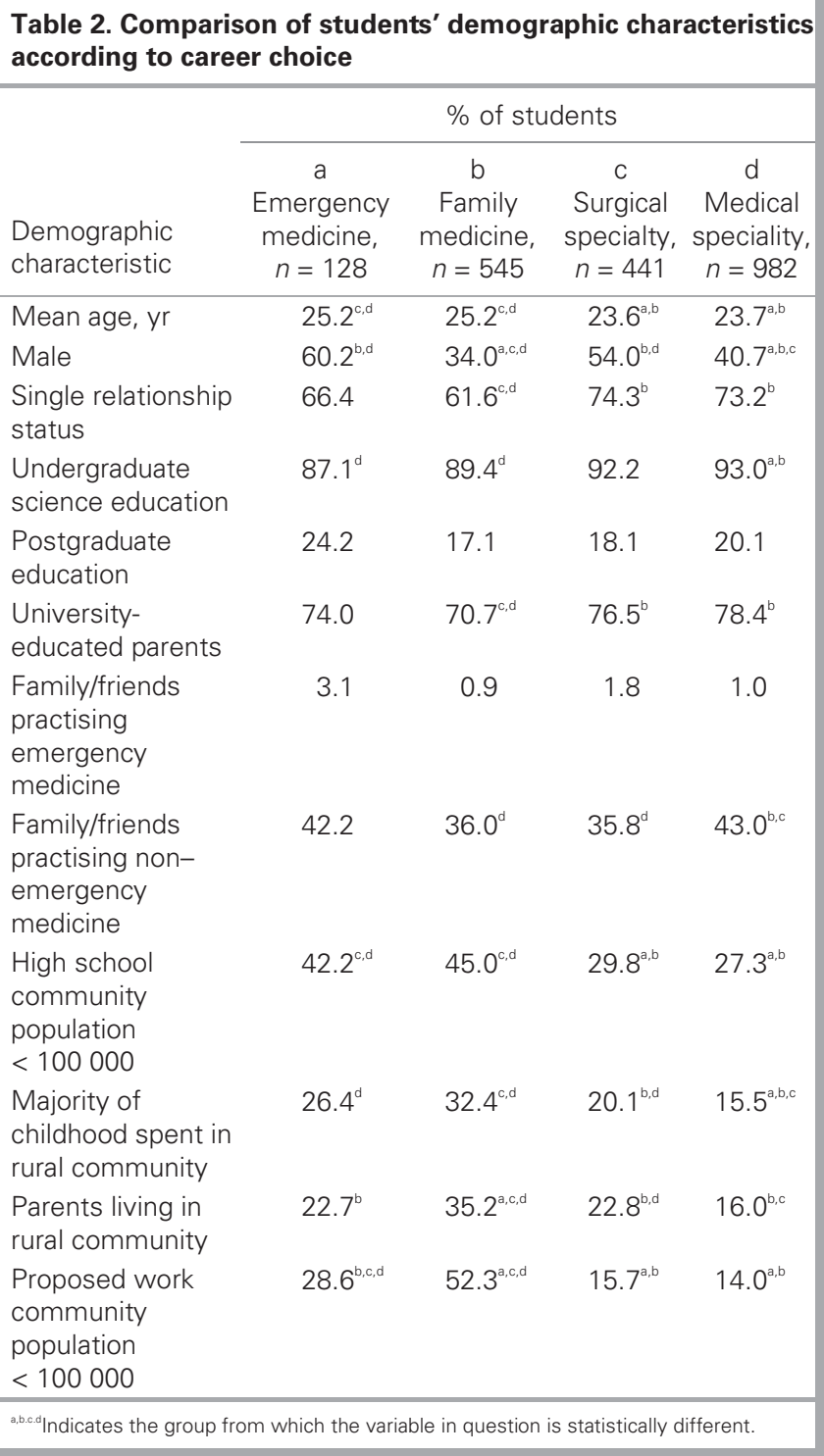


$56.8 \%-61.0 \%)$ considered emergency medicine as a possible career option. For all subsequent comparisons, students are categorized according to their top career choice.

A comparison between the demographic characteristics of students who indicated a primary interest in emergency medicine and of those who indicated a primary interest in other medical specialties, surgical specialties or family medicine are presented in Table 2 .

When we compared the career influences of students primarily interested in emergency medicine with those of students who were primarily interested in other medical specialties, surgical specialties and family medicine, the students interested in emergency medicine fell between the other groups for many of their attributes (Table 1). Students primarily interested in emergency medicine were more influenced by medical lifestyle than those who were interested in surgical specialties. Yet, students interested in emergency medicine resembled those interested in surgical specialties with regard to their comparatively low influence by social orientation and their high influence by hospital orientation. Students interested in emergency medicine were also influenced by the varied scope of practice offered by their career choice, similarly to their colleagues interested in a career in family medicine (Table 3).

\section{DISCUSSION}

Although career intentions at medical school entry are understandably mutable, there is an association between career preference at medical school entry and exit that ranges from $45 \%$ to $70 \% .{ }^{18-20} \mathrm{We}$ found that $6.1 \%$ of the medical students surveyed were primarily interested in a career in emergency medicine at medical school entry, a proportion that equates to 122 students when applied to the 2007 Canadian medical school population of 2000 students. In the 2007 Canadian resident matching service match, there were 152 emergency medicine positions available for Canadian medical graduates (45 FRCP positions and 107 CCFP-EM positions)..$^{21,22}$ Thus based on first-choice interest at medical school entry, there would not appear to be sufficient interest in emergency medicine to fill these positions. Yet in the 2007 match, there were 16 excess first-choice applicants $^{21}$ and 55 excess any-choice applicants ${ }^{23}$ for the available FRCP emergency training positions. Given the current graduating class interest in emergency medicine training, it is logical to conclude that an increase in student interest accrues over the course of the student's undergraduate medical experience. If a desire exists among emergency medicine educators to encourage the maximum number of students to consider a career in emergency medicine, it may be beneficial to clarify what types of students and medical school experiences should be promoted to ensure that the number of applicants for the available emergency medicine positions is maximized.

Our study suggests that entering medical students are interested in emergency medicine for its hospital orientation, medical lifestyle and varied scope of practice. Promotion of these aspects of practice may be advantageous for attracting applicants who are wellsuited to emergency medicine. Role models and prestige were not ranked as important career influences by these students or, in fact, by students primarily interested in any of the other disciplines. It is perhaps not surprising that prestige and role models were not important career influences, as our study examined

\begin{tabular}{|c|c|c|c|c|c|c|}
\hline \multirow[b]{2}{*}{ Factor } & \multicolumn{4}{|c|}{$\%$ of students } & \multicolumn{2}{|c|}{ Results of ANOVA } \\
\hline & $\begin{array}{c}a \\
\text { Emergency } \\
\text { medicine, } \\
n=128\end{array}$ & $\begin{array}{c}\mathrm{b} \\
\text { Family } \\
\text { medicine, } \\
n=545\end{array}$ & $\begin{array}{c}\text { c } \\
\text { Surgical } \\
\text { specialty, } \\
n=441\end{array}$ & $\begin{array}{c}d \\
\text { Medical } \\
\text { specialty, } \\
n=982\end{array}$ & $\mathrm{~F}$ & $p$ value \\
\hline 1. Medical lifestyle & $3.64^{c}$ & $3.86^{c, d}$ & $3.13^{a, b, d}$ & $3.58^{b, c}$ & 62.50 & $<0.001$ \\
\hline 2. Social orientation & $3.24^{\mathrm{b}, \mathrm{d}}$ & $4.14^{a, c, d}$ & $3.09^{b, d}$ & $3.50^{a, b, c}$ & 193.64 & $<0.001$ \\
\hline 3. Prestige & 2.02 & $1.80^{c, d}$ & $2.15^{\mathrm{b}}$ & $2.05^{\mathrm{b}}$ & 16.39 & $<0.001$ \\
\hline 4. Hospital orientation & $3.64^{\mathrm{b}, \mathrm{d}}$ & $2.30^{\mathrm{a}, \mathrm{c}, \mathrm{d}}$ & $3.42^{\mathrm{b}, \mathrm{d}}$ & $2.87^{\mathrm{ab}, \mathrm{bc} c}$ & 198.14 & $<0.001$ \\
\hline 5. Role model & 2.74 & 2.83 & 2.66 & 2.77 & 1.66 & 0.17 \\
\hline 6. Varied scope of practice & $4.25^{\mathrm{cdd}}$ & $4.16^{\mathrm{c}, \mathrm{d}}$ & $2.93^{\mathrm{a}, \mathrm{b}}$ & $3.03^{\mathrm{a}, \mathrm{b}}$ & 243.00 & $<0.001$ \\
\hline
\end{tabular}


the attitudes and attributes of students early in their medical career. The influence of prestige and role models may become important as students get nearer to making their ultimate career choice. A number of studies have found perceived prestige, or lack thereof, to be associated with specific career choices. ${ }^{13,24-27}$ Role models have been found to broadly influence medical career choice. ${ }^{28-30}$ Given that only $2.3 \%$ of students had a close family member or friend practising emergency medicine, it is likely that role models had not yet exerted an influence on career decision-making for most of the study population. Mentoring has been highlighted as an important aspect of career development for medical students specifically interested in emergency medicine, ${ }^{31}$ although career advice related to emergency medicine may not always be positive from faculty, ${ }^{32}$ particularly given the current challenges facing Canadian emergency departments. Advice is more likely to be positive when mentorship is provided by an emergency physician or resident..$^{32,33}$ Duggan and $\mathrm{McNicholl}^{34}$ found that students at one school in the United Kingdom had little knowledge about a career in emergency medicine when compared with other specialties, even after completion of a 3-week rotation. These researchers also reported that emergency medicine was associated with harder work and more stress than other specialties. This perception highlights the importance of appropriate role-modelling.

Our study provides insight into the characteristics of potential future emergency medicine practitioners. Our findings indicate that medical students primarily interested in emergency medicine are predominantly male, are more likely to come from a smaller home town ( $<100000$ population) and plan to work in a smaller community (< 100000 population) when compared with their colleagues who are primarily interested in medical and surgical specialties.

The finding that more men than women are interested in a career in emergency medicine $(60 \%$ v. $40 \%)$ is at variance with the current sex composition of Canadian medical schools, in which approximately $58 \%$ of first year students are women. ${ }^{35}$ Female emergency physicians have been found to resemble female physicians in other specialties, except that they tend to be younger, earn more and report higher job stress. ${ }^{36}$ Therefore, it is not clear why this sex inequity exists in this group of students. Emergency medicine educators may wish to explore the reasons for the predominant male interest in emergency medicine, particularly if they are interested in promoting a wider diversity of providers in the discipline.

The proportion of students inclined toward an emergency medicine career with a reported interest in working in a smaller community is encouraging given the current challenges in providing medical care to rural communities. ${ }^{37}$ This stated interest at medical school entry may wane over time, however, as most emergency training occurs in academic centres with large populations, and the typical location of practice for an individual with an FRCP certification in emergency medicine is an urban centre.

\section{Limitations}

Although this study was carried out at 8 universities, there are regions of Canada that were not represented. Although we undertook a rigorous development and validation process for the survey instrument, there may be important influences that we failed to include. Moreover, the ultimate career choice of the students surveyed is as yet unknown. We are following up the medical school classes that participated in our study to graduation. Follow-up surveys have been distributed to the students at the end of their preclinical years and at the time of their residency match. Once the data has been collected for each of the classes, further analysis will be performed and reported to better understand the decision-making process in its entirety from entry to residency. Thus this study is perhaps best viewed as providing a window into the minds of a subset of Canadian medical students who entered medical school between 2001 and 2004. Finally, we did not ask students to specify whether their interests were more toward an FRCP or CCFP-EM certification, and as a result, a subanalysis of this nature is not possible. Discussion and debate continues in the emergency medicine community regarding the current 2 routes of emergency medicine certification in Canada, the pros and cons of a unified training stream, and the impact of the current system on the growth of the specialty. ${ }^{1,38}$

\section{CONCLUSION}

Students primarily interested in a career in emergency medicine at medical school entry have attributes that differentiate them from students primarily interested in family medicine, the surgical specialties or the medical specialties. These findings may help guide future initiatives regarding emergency medicine education. 
Competing interests: None declared.

\section{REFERENCES}

1. Rutledge T. Emergency medicine training in Canada: learning from the past to prepare for the future. CJEM 2008;10: 108-10.

2. Chapman D, Char D, Aubin C. Chapter 10, Clinical decision making. In: Rosen's emergency medicine: concepts and clinical practice. 6th ed. Marx JA, Hockberger RS, Walls RM Eds. Philadelphia (PA): Mosby/Elsevier; 2006. p. 125-142.

3. Letovsky E. Do's and don'ts of emergency medicine: a primer for residents. CJEM 2003;5:130-2.

4. Lloyd S, Streiner D, Shannon S. Demographic characteristics of full-time emergency physicians in Canada. Am $\mathrm{J}$ Emerg Med 1993;11:364-70.

5. Operations: reports \& statistics $-R-1$ match reports 2000-2007. Ottawa (ON): Canadian Resident Matching Service. Available: www.carms.ca/eng/operations_R1stat_e.shtml (accessed 2009 Mar 31).

6. National Residency Matching Program (NRMP). Advance data tables 2008 main residency match table 1 match summary. Washington (DC): The Program; 2008. Available: www .nrmp.org/data/advancedatatables2008.pdf (accessed 2009 Mar 31).

7. Chapman JJ, Weiss SJ, Haynes ML, et al. Impact of EMS education on emergency medicine ability and career choices of medical students. Prehosp Emerg Care 1999;3:163-6.

8. Dorsey ER, Jarjoura D, Rutecki GW. The influence of controllable lifestyle and sex on the specialty choices of graduating U.S. medical students, 1996-2003. Acad Med 2005;80: 791-6.

9. Schwartz RW, Haley JV, Williams C, et al. The controllable lifestyle factor and students' attitudes about specialty selection. Acad Med 1990;65:207-10.

10. Kazzi AA, Langdorf MI, Ghadishah D, et al. Motivations for a career in emergency medicine: a profile of the 1996 US applicant pool. CJEM 2001;3:99-104.

11. Zun LS, Downey L. Is a third year clerkship in emergency medicine correlated with a career choice in emergency medicine? Teach Learn Med 2004;16:14-7.

12. Scott IM, Matejcek AN, Gowans M, et al. Choosing a career in surgery: factors that influence Canadian medical students' interest in pursuing a surgical career. Can J Surg 2008;51: 371-7.

13. Scott I, Wright B, Brenneis F, et al. Why would I choose a career in family medicine?: reflections of medical students at 3 universities. Can Fam Physician 2007;53:1956-7.

14. Scott I, Gowans MC, Wright B, et al. Why medical students switch careers: changing course during the preclinical years of medical school. Can Fam Physician 2007;53:95, 95:e.1-5, 94.

15. Wright B, Scott I, Woloschuk W, et al. Career choice of new medical students at three Canadian universities: family medicine versus specialty medicine. CMAJ 2004;170:1920-4.

16. Wright B, Scott I, Powis D, et al. Career preferences of new medical students at four Australian universities: rural family medicine versus the rest. Aust 7 Rural Health 2006;14:229-30.

17. Canadian Institute for Health Information. Table 1. Urbanrural number of physicians by specialty, Canada, 2004. Ottawa (ON): The Institute; 2006. Available: http://secure.cihi.ca/
cihiweb/dispPage.jsp?cw_page=media_11jan2006_tab1_e (accessed 2009 Apr 1).

18. Zeldow PB, Preston RC, Daugherty SR. The decision to enter a medical specialty: timing and stability. Med Educ 1992; 26:327-32.

19. Carline JD, Greer T. Comparing physicians' specialty interests upon entering medical school with their eventual practice specialties. Acad Med 1991;66:44-6.

20. DeWitt DE, Curtis JR, Burke W. What influences career choices among graduates of a primary care training program? 7 Gen Intern Med 1998;13:257-61.

21. Discipline choices of Canadian applicants. 2007 first iteration $P G Y-1$ match. Ottawa (ON): Canadian Resident Matching Service; 2007. Available: www.carms.ca/pdfs/2007Match Results/Discipline_Choices_of_Canadian_Applicants_en.pdf (accessed 2009 Apr 1).

22. Positions available and applicants by residency institution. 2007 family medicine/emergency medicine match. Ottawa (ON): Canadian Resident Matching Service; 2007. Available: www .carms.ca/pdfs/2007R3_MatchResults/Positions\%20Available \%20and\%20Applicants\%20by\%20Residency\%20Institution _en.pdf (accessed 2009 Apr 1).

23. Active Canadian application counts byd. 2007 first iteration PGY1 match. Ottawa (ON): Canadian Resident Matching Service; 2007. Available: www.carms.ca/pdfs/2007MatchResults/ Active_Canadian_Application_Counts_by_Discipline_en.pdf (accessed 2008 Apr 1).

24. Norredam M, Album D. Prestige and its significance for medical specialties and diseases. Scand J Public Health 2007; 35:655-61.

25. Newton DA, Grayson MS, Whitley TW. What predicts medical student career choice? J Gen Intern Med 1998;13: 200-3.

26. Schafer S, Shore W, French L, et al. Rejecting family practice: why medical students switch to other specialties. Fam Med 2000;32:320-5.

27. Malhi GS, Parker GB, Parker K, et al. Shrinking away from psychiatry? A survey of Australian medical students' interest in psychiatry. Aust N Z J Psychiatry 2002;36:416-23.

28. Burack JH, Irby DM, Carline JD, et al. A study of medical students' specialty-choice pathways: trying on possible selves. Acad Med 1997;72:534-41.

29. Mutha S, Takayama JI, O’Neil EH. Insights into medical students' career choices based on third- and fourth-year students' focus-group discussions. Acad Med 1997;72:635-40.

30. Wright S, Wong A, Newill C. The impact of role models on medical students. 7 Gen Intern Med 1997;12:53-6.

31. Garmel GM. Mentoring medical students in academic emergency medicine. Acad Emerg Med 2004;11:1351-7.

32. Blumstein HA, Cone DC. Medical student career advice related to emergency medicine. Acad Emerg Med 1998;5:69-72.

33. Gallagher EJ, Goldfrank LR, Anderson GV Jr, et al. Role of emergency medicine residency programs in determining emergency medicine career choice among medical students. Ann Emerg Med 1994;23:1062-7.

34. Duggan BJ, McNicholl BP. Medical students' attitudes at one school toward accident and emergency medicine as a career. Acad Med 1998;73:347.

35. Association of Faculties of Medicine of Canada (AFMC). Canadian medical education statistics 2007: Table 8. Enrollment in Canadian faculties of medicine by sex 1968/67-2006/07 
Ottawa (ON): The Association; 2007. p. 10. Available: www .afmc.ca/pdf/CanadianMedicalEducationStatistics2007.pdf (accessed 2009 Apr 1).

36. Frank E, Totten V, Andrew L. Characteristics of women emergency physicians. The Internet Journal of Emergency and Intensive Care Medicine 2000;4.

37. Rourke J. Increasing the number of rural physicians. CMAJ 2008;178:322-5.
38. Abu-Laban RB. Emergency medicine certification in Canada: the years march on but the questions remain the same. CJEM 2008;10:101-3.

Correspondence to: Dr. Ian Scott, Undergraduate Family Practice Programs Director, University of British Columbia, David Strangway Bldg, 300-5950 University Blvd., Vancouver BC V6T 1Z3; ian.scott@familymed.ubc.ca

\section{Appendix 1. Questionnaire: how medical students choose (Part 1 of 4)}

1. As you are in the first weeks of medical school please tell us which residencies you currently are considering entering.

Check "Yes" to any you would consider.

Check "No" if you are certain you would not have considered the program.

Next, rank your top three "Yes" choices in order of preference.

Yes No Rank top three

a. Emergency

b. Urban Family Medicine

c. Rural Family Medicine

d. Internal Medicine (or its subspecialties)

e. Obstetrics \& Gynaecology

f. Pediatrics (or its subspecialties)

g. Psychiatry

h. Surgery (or its subspecialties)

i. Other

j. Do not have any preference

2. On a scale of $1-5(1=$ no influence, $3=$ moderate influence, $5=$ major influence $)$, how did the following factors influence you in your preferring the number one ranked choice of residency you stated in Question 1 (i.e. your present 1st choice)? We would like to know how you think the following factors influenced your career choice (not necessarily your specific residency choice). Please circle a number.

a) A wide variety of patient problems encompassing a wide range of age groups is interesting to me.
1
2
3
4
5

b) I prefer to focus on a narrower variety of patient problems and/or (a) more focused age group(s).
12
23
4
5

c) Supervisors/tutors/lecturers have told me my career choice is a good match for my skill set/intelligence.
1
2
3
4
5

d) My career choice will allow me to work with a patient population that is interesting/stimulating.
1
2
3
4
5

e) My chosen career will allow me to focus on in-hospital care.
1
3
4
5

f) My chosen career will allow me to focus on patients/clinics in the community.
1
2
4
5

g) My chosen career will allow me to focus on urgent care.
1

h) My chosen career will allow me to focus on non-urgent care.
1
2
3
5

i) I prefer to see the immediate results of my therapeutic interventions and my chosen career will allow me to experience this.
2
3
4
5

1

j) My debt accumulated to date and from what I expect to accumulate from my continued education is expected to be high and I will need a practice that will provide an adequate income to eliminate this debt.
2
3
4
5

1

k) My chosen career will have a high income potential and this is important to me irrespective of my debt.
1
2
4
5

I) Immediate results from my therapeutic interventions are not as important as developing a long-term relationship with my patients and my chosen career will allow this relationship to develop.
1
2
3
4
5 


\section{Appendix 1. Questionnaire: how medical students choose (Part 2 of 4)}

m) My chosen career will provide me with status among my future colleagues.
2
3
4
5

n) My chosen career will have an acceptable on-call schedule.
1
2
3
4
5

o) I don't like dealing with uncertainty in my clinical work and this career choice will reduce my discomfort with uncertainty.
1
2
3
4
5

p) I would sooner deal with medical problems than social or psychological problems and my chosen career will allow me to do this.
$1 \quad 2$
23
4
5

q) I met (a) physician(s) prior to coming to medical school who I wish to emulate and as such I have chosen to follow them in their career(s).
12
23
4
5

r) I have an interest in research and I will be able to do research as part of my chosen career.
1
2
3
4
5

s) My social commitment to society has lead me to my chosen career.
1
2
3
4
5

t) Supervisors/tutors/lecturers have told me my career choice will have a more stable/secure future than other career choices.
1
2
3
4
5

u) I have an interest in promoting health and my chosen career will allow me to do this.
1
2
3
4
5

v) My chosen career will have acceptable hours of practice.
1
2
3
4
5

w) My chosen career will provide me flexibility in what I wish to do in medicine.
1
2
3
4
5

x) My chosen career will provide me flexibility in my ability to do other non-medical things.
1
2
3
4
5

y) My chosen career will allow me to keep my options open.
1
2
3
4
5

z) Meaningful experiences with a physician in the past (positive and/or negative) lead me to my current career choice.
1
2
3
4
5

aa) An expected short postgraduate training period led me to my current career choice.
1
2
3
4
5

bb) An expected less intense residency (not necessarily shorter) led me to my current career choice.
1
2
3
4
5

cc) Experiences in health or health related fields prior to medical school led me to my current career choice.
2
3
4
5

1

dd) Experiences or interactions with role models or mentors prior to medical school led me to my current career choice.
1
2
3
4
5

ee) When in practice, I want to be able to spend appropriate time with my family and this has led me to my current career choice.
1
2
3
4
5

ff) Other, please specify

$12 \quad 3 \quad 345$

gg) Other, please specify

12

2

4

5

5

hh) What size of community do you envision yourself working in after completion of your training?
1.__ > 500000
2.__ $100000-500000$
3.__ $50000-100000$
4.__ $10000-50000$
5.__ < $<10000$
6.___Undecided 


\section{Appendix 1. Questionnaire: how medical students choose (Part 3 of 4)}

Your demographics

a. Gender male_female_

b. Age

c. Relationship status (Check one)

i.__ married/engaged/long-term partner/common-law

ii.__ single

iii.__ divorced

iv. widowed

d. If you have a partner, partner's occupation

e. Number of dependants you have

f. Your past education (Check all that apply)

1.___ Bachelor of Science

2.__ Bachelor of Engineering

3.__ Bachelor of Arts

4.__ Masters of Science

5.__ Masters

6. PhD

7.___other in

g. What was the population of the city/town where you last attended high school (or spent most of your growing up that had an influence on who you are)? (Check one)

1.__ (> 500000$)$

2. $(100000-500000)$

3.__ (50 $000-100000)$

4. $(10000-50000)$

5.__ $(<10000)$

h. During your childhood, what percentage of your time was spent in rural communities?

$0 \%$ $1 \%-25 \%$ $26 \%-50 \%$ $>50 \%$

i. If you have 1st degree relatives/close family friends who are physicians please tell us the relationship and what type of medicine they are in (list as yes - Aunt, yes — Friend, etc.)

1. Family medicine

2. Internal medicine

3. Surgery

4. Pediatrics

5. Other

j. Do any of your family members currently live or work in rural area?
1. Parents Yes
No
2. Siblings Yes
3. Grandparents
No
Yes__ No_

k. What is the highest level of education that your most educated parent/guardian attained (check one)?

1. Less than high school

2. High school

3. Diploma/degree from postsecondary college or technical school

5. Undergraduate university degree

6. Postgraduate university degree

I. What experience in the health field did you have prior to medicine? (Check all that apply)

1.___Employment

2.___ Volunteering

3.__ Major health problem

4.___ Family member was a patient

5.___ Other (Please specify)

6. None 
Scott et al.

\section{Appendix 1. Questionnaire: how medical students choose (Part 4 of 4)}

m. Have you ever lived or traveled in a developing country (Third World country) for more than two months? Yes No

$\mathrm{n}$. What types of volunteer activities have you been involved with in the past? (Check all that apply)

1.__ Programs for the elderly

2.__Children/youth programs

3.___Persons with mental illnesses

4.___Persons with physical disabilities

5.___Persons with cognitive disabilities

6.__Hospital-based volunteer programs

7.___Inner city programs

8._Crisis hotlines

9.___ Sports programs

10.__ Volunteer work in developing nations

11._Other, please specify

o. Your name (We require this for our follow-up survey in 2 years and should we wish to invite you to a focus group in the future)

(Last, First — Printed please) 